\title{
Avaliação de desempenho de concreto leve com adição de Poliestireno Expandido (EPS): revisão de literatura
}

O setor da construção civil sempre foi marcado por demandar grande quantidade de recursos naturais, geralmente impulsionado pela necessidade da construção de moradias e edificações, tornando-se um dos ramos industriais que mais consomem matéria-prima, chegando a se apropriar de cerca de $50 \%$ destes recursos. Logo, a construção sustentável é a principal aposta para a melhoria dos índices alarmantes deste setor industrial com relação à preservação do meio ambiente. Assim, este trabalho tem como foco a utilização de matérias recicláveis como agregado na produção de concreto leve. Atualmente, existe diversas linhas de pesquisas acadêmicas a respeito deste tema. Neste contexto, a adição de Poliestireno Expandido (EPS) no concreto vêm demostrando resultados satisfatórios a respeito de resistência, qualidade de acabamento e redução do peso próprio dos componentes das edificações. Este trabalho tem por finalidade expor as vantagens e desvantagens da adição de EPS como agregado do concreto, bem como o seu desempenho térmico e sua resistência mecânica, com base em uma revisão de literatura que aborde o tema tratado. Com base nessa revisão de literatura, concluiu-se que a adição de EPS torna-se vantajosa por diminuir o peso próprio da estrutura, reduzindo a quantidade de material necessário para resistir aos esforços, além de toda a contribuição ao meio ambiente, por poupar recursos naturais e ainda permitindo a possibilidade de se utilizar resíduos recicláveis de EPS na sua produção.

Palavras-chave: Concreto com EPS; Concreto leve; Desempenho térmico; Sustentabilidade.

\section{Evaluation of light concrete performance with addition of Expanded Polystyrene (EPS): literature review}

\begin{abstract}
The civil construction sector has always been marked by demanding a large amount of natural resources, usually driven by the need to build houses and buildings, making it one of the industrial sectors that consume the most raw materials, reaching the appropriation of around $50 \%$ these resources. Therefore, sustainable construction is the main bet for improving the alarming rates of this industrial sector in relation to the preservation of the environment. Thus, this work focuses on the use of recyclable materials as an aggregate in the production of light concrete. Currently, there are several lines of academic research on this topic. In this context, the addition of Expanded Polystyrene (EPS) to concrete has been showing satisfactory results regarding strength, quality of finish and reduction of the own weight of building components. This work aims to expose the advantages and disadvantages of adding EPS as a concrete aggregate, as well as its thermal performance and its mechanical resistance, based on a literature review that addresses the topic addressed. Based on this literature review, it was concluded that the addition of EPS becomes advantageous because it reduces the structure's own weight, reducing the amount of material needed to resist efforts, in addition to all the contribution to the environment, by saving resources and also allowing the possibility of using recyclable EPS waste in their production.
\end{abstract}

Keywords: EPS concrete; Lightweight concrete; Thermal performance; Sustainability.

Topic: Engenharia de Construção Civil

Reviewed anonymously in the process of blind peer
Received: 07/08/2020

Approved: $\mathbf{2 1 / 1 1 / 2 0 2 0}$
Rhaylla Cristielly Rêgo de Sousa

Instituto Tocantinense Presidente Antônio Carlos, Brasil

http://lattes.cnpq.br/1436320238015118

rhayllacristielly@hotmail.com

Diogo Pedreira Lima (iD

Instituto Tocantinense Presidente Antônio Carlos, Brasil

http://lattes.cnpq.br/7967728577417186

http://orcid.org/0000-0002-3849-2587

diogopedreira@itpac.com.br

Medson Dewictor Raphael Turíbio Aguiar Silva

Instituto Tocantinense Presidente Antônio Carlos, Brasil

http://lattes.cnpq.br/2466832694070399

medson-job@hotmail.com
Referencing this:

SOUSA, R. C. R.; LIMA, D. P.; SILVA, M. D. R. T. A.. Avaliação de desempenho de concreto leve com adição de Poliestireno Expandido (EPS): revisão de literatura. Engineering Sciences, v.8, n.3, p.45-52, 2020. DOI: http://doi.org/10.6008/CBPC2318-3055.2020.003.0005 


\section{INTRODUÇÃO}

O conceito de construção sustentável vem ganhando cada vez mais notoriedade no cenário mundial sobre a minimização dos impactos ambientais. O setor da construção civil sempre foi marcado por demandar grande quantidade de recursos naturais, geralmente impulsionado pela necessidade da construção de moradias e edificações.

Em decorrência disto, a construção civil torna-se um dos ramos industriais que mais consomem matéria-prima, chegando a se apropriar de cerca de 50\% destes recursos. Logo, a construção sustentável é a principal aposta para melhorar os índices tão preocupantes deste setor industrial com relação a preservação do meio ambiente (NEVES et al., 2018).

Ao longo das décadas, o setor da construção civil tem sido pressionado a adotar medidas sustentáveis em seus processos produtivos, seja por iniciativas governamentais, por influência de mercado ou por consciência social. Por consequência disso, para se adaptar a essas novas exigências sustentáveis, a indústria da construção deve readequar as metodologias de produção e gestão de suas obras.

A construção sustentável se divide em cinco pilares; o primeiro é a elaboração de projetos inteligentes onde é aproveitado a luz natural para iluminação interna das edificações. O segundo é gerenciamento da emissão resíduos provenientes da construção. O terceiro pilar é a produção de obras com autossuficiência energética. O quarto seguimento é utilização de materiais ecológicos produzidos com resíduos recicláveis. E por fim o quinto pilar que quem tem por finalidade utilizar a água proveniente da chuva (ROHAN et al., 2016).

Este trabalho tem como foco o quarto pilar da construção sustentável, a utilização de matérias recicláveis como agregado na produção de concreto leve. Atualmente existe diversas linhas de pesquisas acadêmicas a respeito deste tema. E a adição de Poliestireno Expandido (EPS) no concreto vem demostrando resultados satisfatórios a respeito de resistência, qualidade de acabamento e redução do peso próprio dos componentes das edificações, implicando em menos cargas nas fundações, garantindo segurança e economia na obra (GOMES et al., 2015).

Entretanto, o setor da construção civil é altamente conservador e a entrada de inovações construtivas é um grande entrave da introdução de medidas sustentáveis na indústria da construção. Sendo assim, este trabalho tem por finalidade expor as vantagens e desvantagens da adição de EPS como agregado do concreto, bem como o seu desempenho térmico e sua resistência mecânica com base em uma revisão de literatura que aborde o tema tratado.

\section{METODOLOGIA}

Estudos de revisão da literatura são especialmente úteis para se verificar o estado d'arte acerca de um dado fenômeno ou tema de interesse. Do ponto de vista metodológico, podem ser realizados 3 tipos de revisão da literatura (CORDEIRO et al., 2007).

A revisão narrativa da literatura, na qual não se tem um rigor quanto a busca dos achados, ficando o 
pesquisador livre para buscar as fontes disponíveis com maior acessibilidade. A revisão sistemática da literatura, que requer maior rigor metodológico, e tem como ponto dificultador a necessidade de um grupo de pesquisa ou, no mínimo, dois pesquisadores trabalhando de forma independente e ao mesmo tempo interligados (CORDEIRO et al., 2007).

Por fim, a revisão integrativa da literatura, que embora possa ser realizada por somente um pesquisador, também exige um rigor na busca dos achados. Este tipo de revisão auxilia no processo de compreendimento de determinados assuntos ou fenômeno. A grande vantagem é a possibilidade de se realizar uma análise sintetizada que permite conclusões gerais a respeito do tema (NEVES et al., 2018).

Dada a natureza deste estudo, optou-se pela metodologia de revisão integrativa de literatura, que atende às necessidades de fundamentação ao levantamento bibliográfico. Assim, a presente pesquisa é desenvolvida a partir de materiais publicados em livros e artigos, visando o aprofundamento do estudo em questão.

Para direcionar a revisão integrativa, construiu se a seguinte questão: Qual o desempenho esperado em edificações que utilizam elementos pré-moldados de concreto leve com adição de EPS em comparação com o concreto convencional?

Nesta revisão de literatura foram utilizados artigos das bases de dados Scielo, Google Scholar e Biblioteca Digital Brasileira de Teses e Dissertações (BDTD), além de livros e artigos referentes ao tema. 0 levantamento e seleção dos artigos que serviram como embasamento teórico, foram coletados durante os meses de março, abril e maio de 2020. Para a pesquisa, foram selecionados artigos no idioma, português, a partir do ano de 2003 até o ano de 2020. Utilizou-se as palavras-chave: Concreto com EPS, concreto leve, desempenho térmico, sustentabilidade e resistência. Os critérios de inclusão foram a leitura completa dos artigos baseados no ano de publicação, língua portuguesa, artigos relacionados com o tema de concreto com adição de poliestireno expandido (EPS), artigos com disponibilização completas.

Os critérios de exclusão foram os estudos que não apresentaram boa qualidade metodológica ou não abordaram diretamente o tema, além de idioma que não foram o português. Essa pesquisa foi coletada por três pesquisadores com a finalidade de descrever as vantagens e desvantagens da utilização de concreto leve na construção civil.

Foram selecionados um total de 54 artigos, sendo 12 encontrados na base de dados Scielo, 34 artigos no Google Scholar e 8 artigos na Biblioteca Digital Brasileira de Teses e Dissertações (BDTD), utilizando as palavras chaves: Concreto com EPS, concreto leve, desempenho térmico, sustentabilidade e resistência. A primeira triagem foi dos títulos, onde 42 artigos foram selecionados para leitura do resumo. Após a leitura dos resumos destes artigos, 28 foram exclusos por não se tratarem do tema proposto. Dos 14 restantes, 2 foram exclusos por se tratarem de artigos duplicados. Sendo selecionados 12 artigos para leitura na íntegra. Após a leitura crítica, foram selecionados 11 trabalhos que se mostraram adequados para compor a discussão teórica desta pesquisa. 


\section{DISCUSSÃO TEÓRICA}

No quadro 1 é apresentado os principais dados encontrados nas referências que compuseram a amostra, sendo descrito os autores, o ano de publicação, o tipo de metodologia utilizada, o principal objetivo e os principais resultados encontrados.

Assim, o estudo mostrou que predominaram nos artigos publicados, a metodologia de ensaios de laboratório $(54,54 \%)$, revisões de literatura $(27,27 \%)$ e estudos de casos $(18,19 \%)$. Isso comprova a escassez de revisões bibliográficas e de inovações tecnológicas a respeito da adição de EPS como agregado na produção de concreto leve.

Quadro 1: Relação de artigos analisados, com foco na adição de EPS como agregado na produção de concreto leve.

\begin{tabular}{|c|c|c|c|}
\hline Autor & Metodologia & Objetivo & Resultados \\
\hline $\begin{array}{l}\text { MORAES et } \\
\text { al. (2015) }\end{array}$ & $\begin{array}{ll}\text { Revisão } & \text { de } \\
\text { literatura. } & \end{array}$ & $\begin{array}{l}\text { Explorar os aspectos gerais do Poliestireno } \\
\text { Expandido (EPS) dentro do contexto de } \\
\text { sustentabilidade, e analisar suas } \\
\text { possibilidades dentro da construção civil, } \\
\text { um dos maiores consumidores de recursos } \\
\text { naturais, causando com isto um grande } \\
\text { impacto no meio ambiente. }\end{array}$ & $\begin{array}{l}\text { O poliestireno expandido quando exposto a } \\
\text { temperaturas acima de } 80 \text { oc } \text {, começa a ter seu } \\
\text { núcleo degradado. Em caso de incêndio, tais } \\
\text { valores são facilmente superados e, com o núcleo } \\
\text { danificado, há perda de estabilidade da } \\
\text { edificação. Ressaltam que os materiais indicados } \\
\text { para esses casos são os que têm núcleos } \\
\text { compostos por poliuretano (PUR) e } \\
\text { poliisocianurato (PIR). }\end{array}$ \\
\hline $\begin{array}{l}\text { ROCHA et al. } \\
\text { (2016) }\end{array}$ & $\begin{array}{l}\text { Ensaio de } \\
\text { laboratório. }\end{array}$ & $\begin{array}{l}\text { Analisar o concreto leve com a } \\
\text { substituição do agregado graúdo pelo EPS, } \\
\text { por não ser solúvel em água e não liberar } \\
\text { substâncias ao meio ambiente, pode se } \\
\text { tornar um agregado leve alternativo e a } \\
\text { solução para a redução de impactos } \\
\text { ambientais. }\end{array}$ & $\begin{array}{l}\text { A resistência à compressão do traço usado como } \\
\text { referência obteve resultado de } 21,13 \mathrm{MPa} \text { aos } 28 \\
\text { dias. Portanto possibilitando influência de não } \\
\text { consideradas as quantidades de umidade da } \\
\text { areia utilizada nos traços produzidos. A } \\
\text { substituição do agregado graúdo EPS, mostrou- } \\
\text { se viável para o emprego de concreto que } \\
\text { necessite de resistência de } 20 \mathrm{MPa} \text {, para traço de } \\
5 \% \text { atingindo resistência média de } 20,53 \mathrm{MPa} \text {, e } \\
\text { o traço de } \\
10 \% \text { atingindo resistência média de } 20,21 \mathrm{MPa} \text {. }\end{array}$ \\
\hline $\begin{array}{l}\text { DANTAS et al. } \\
\text { (2019) }\end{array}$ & $\begin{array}{ll}\text { Revisão } & \text { de } \\
\text { literatura. } & \end{array}$ & $\begin{array}{l}\text { Comparar as propriedades físico } \\
\text { mecânicas do concreto com adição de } \\
\text { esferas de Poliestireno Expandido em } \\
\text { diferentes proporções, bem como a } \\
\text { análise das adições, aditivos e demais } \\
\text { materiais para a fabricação do concreto } \\
\text { leve. }\end{array}$ & $\begin{array}{l}\text { Através de experimentos que determinam a } \\
\text { condutividade térmica e o calor específico, há } \\
\text { vantagens com relação ao desempenho térmico } \\
\text { os sistemas construídos com blocos de EPS, } \\
\text { devido esse agregado leve reduzir a transferência } \\
\text { de calor do meio externo para o meio interno, } \\
\text { resultando em uma economia de energia elétrica } \\
\text { necessária à climatização de ambientes. }\end{array}$ \\
\hline $\begin{array}{l}\text { SILVA et al. } \\
\text { (2017) }\end{array}$ & $\begin{array}{l}\text { Ensaio de } \\
\text { laboratório. }\end{array}$ & $\begin{array}{l}\text { Demonstrar os benefícios da utilização do } \\
\text { EPS na construção civil. }\end{array}$ & $\begin{array}{l}\text { O traço convencional obteve um resultado bem } \\
\text { acima do necessário, apenas uma das misturas } \\
\text { com substituição de EPS não obteve a resistência } \\
\text { necessária, porém obteve-se um concreto leve } \\
\text { de fácil confecção e colaborando com o meio } \\
\text { ambiente. }\end{array}$ \\
\hline $\begin{array}{l}\text { BEZERRA } \\
(2003)\end{array}$ & Estudo de caso. & $\begin{array}{l}\text { Fornecer informações acerca da } \\
\text { caracterização, sob o ponto de vista } \\
\text { térmico, dos sistemas construtivos } \\
\text { fabricados a partir do concreto leve. }\end{array}$ & $\begin{array}{l}\text { Os resultados permitiram relacionar } \\
\text { quantitativamente o efeito do EPS como } \\
\text { agregado em elementos construtivos na redução } \\
\text { da taxa de transferência de calor em função da } \\
\text { variação de densidade, que também interfere } \\
\text { nas outras propriedades térmicas e mecânicas do } \\
\text { material, como comprovado. Constatou-se que } \\
\text { as paredes de concreto leve apresentaram } \\
\text { melhor desempenho térmico do que os outros } \\
\text { dois sistemas construtivos consagrados } \\
\text { comercialmente. }\end{array}$ \\
\hline $\begin{array}{l}\text { XAVIER et al. } \\
\text { (2016) }\end{array}$ & $\begin{array}{l}\text { Ensaio de } \\
\text { laboratório. }\end{array}$ & $\begin{array}{l}\text { Avaliar as propriedades físicas do concreto } \\
\text { leve estrutural com EPS reciclado, através } \\
\text { de }\end{array}$ & $\begin{array}{l}\text { O EPS diminuiu consideravelmente o abatimento } \\
\text { do concreto, que define sua trabalhabilidade, } \\
\text { portanto aumentando o teor de EPS no concreto }\end{array}$ \\
\hline
\end{tabular}




\begin{tabular}{|c|c|c|c|}
\hline & & ensaios laboratoriais. & $\begin{array}{l}\text { e mantendo o fator água/cimento o resultado } \\
\text { será um concreto menos trabalhável. }\end{array}$ \\
\hline $\begin{array}{l}\text { CARVALHO } \\
\text { et al. (2019) }\end{array}$ & $\begin{array}{l}\text { Ensaio de } \\
\text { laboratório. }\end{array}$ & $\begin{array}{l}\text { Produzir misturas de concreto com esferas } \\
\text { de EPS e partículas de EPS reciclado a fim } \\
\text { de avaliar e comparar suas propriedades } \\
\text { no estado fresco e endurecido para } \\
\text { aplicação em paredes estruturais de } \\
\text { edificações }\end{array}$ & $\begin{array}{l}\text { A resistência à compressão do concreto com EPS } \\
\text { aumenta com a diminuição do diâmetro das } \\
\text { esferas de EPS para uma mesma densidade. Por } \\
\text { exemplo, concretos com densidade de } 1000 \\
\mathrm{~kg} / \mathrm{m}^{3} \text { e esferas de } 7 \mathrm{~mm} \text {, mostraram diminuição } \\
\text { de } 35 \% \text { na resistência à compressão em } \\
\text { comparação com a mesma mistura, mas com } \\
\text { esferas de poliestireno de } 1 \mathrm{~mm} \text {. }\end{array}$ \\
\hline $\begin{array}{l}\text { MONCADA et } \\
\text { al. (2019) }\end{array}$ & $\begin{array}{l}\text { Ensaio de } \\
\text { laboratório. }\end{array}$ & $\begin{array}{l}\text { Analisar a influência da argila expandia e } \\
\text { EPS no concreto, o programa } \\
\text { experimental concebeu se na elaboração } \\
\text { de corpos de prova a análise de resistência } \\
\text { mecânica, a fim de expor seu fator de } \\
\text { eficiência. }\end{array}$ & $\begin{array}{l}\text { A restringência do valor da massa específica no } \\
\text { concreto leve composto por argila expandida e } \\
\text { EPS é a principal característica para que ele possa } \\
\text { ser um material viável a ser utilizado em } \\
\text { construções. Além de minimizar as solicitações } \\
\text { dos esforços, a massa específica sendo reduzida } \\
\text { em relação ao concreto convencional, facilita o } \\
\text { transporte e o lançamento do concreto nas } \\
\text { construções. Com isso pode se dizer que trará } \\
\text { uma maior feracidade no canteiro de obras. }\end{array}$ \\
\hline $\begin{array}{l}\text { ROCHA et al. } \\
(2016)\end{array}$ & $\begin{array}{lr}\text { Revisão } & \text { de } \\
\text { literatura } & \text { e } \\
\text { ensaio } & \text { de } \\
\text { laboratório. } & \end{array}$ & $\begin{array}{l}\text { Analisar o concreto leve com a } \\
\text { substituição do agregado graúdo pelo EPS, } \\
\text { por não ser solúvel em água e não liberar } \\
\text { substâncias ao meio ambiente, pode se } \\
\text { tornar um agregado leve alternativo e } \\
\text { uma solução para a redução de impactos } \\
\text { ambientais. }\end{array}$ & $\begin{array}{l}\text { A substituição do agregado graúdo EPS, mostrou- } \\
\text { se viável para o emprego de concreto que } \\
\text { necessite de resistência de } 20 \mathrm{MPa} \text {, para o traço } \\
\text { de } 5 \% \text { atingindo resistência média de } 20,53 \mathrm{MPa} \text {, } \\
\text { e o traço de } 10 \% \text { atingindo resistência média de } \\
20,21 \mathrm{MPa} \text {. }\end{array}$ \\
\hline $\begin{array}{l}\text { KUMAYAMA } \\
\text { et al. (2015) }\end{array}$ & $\begin{array}{l}\text { Ensaio de } \\
\text { laboratório. }\end{array}$ & $\begin{array}{l}\text { Avaliar do resíduo de pó de mármore } \\
\text { como finos nas propriedades do concreto } \\
\text { auto-adensável, e do resíduo de EPS, } \\
\text { quando considerado o concreto nos } \\
\text { estados fresco e endurecido, de modo a se } \\
\text { considerar a validação dos concretos em } \\
\text { termos do atendendo das exigências para } \\
\text { com o CAA, e de se compreender o } \\
\text { desempenho potencial do concreto } \\
\text { endurecido. }\end{array}$ & $\begin{array}{l}\text { Os resultados no estado fresco se apresentaram } \\
\text { de modo a validar as propriedades requeridas } \\
\text { para o CAA. No estado endurecido observou-se a } \\
\text { diminuição dos valores de resistência à } \\
\text { compressão simples e diametral, e o aumento } \\
\text { dos valores da absorção, com o incremento do } \\
\text { teor de EPS em substituição. }\end{array}$ \\
\hline $\begin{array}{l}\text { GOMES et al. } \\
\text { (2015) }\end{array}$ & Estudo de caso. & $\begin{array}{l}\text { Analisar como algumas propriedades dos } \\
\text { agregados reciclados influenciam no } \\
\text { comportamento do concreto leve nos } \\
\text { estados fresco e endurecido. }\end{array}$ & $\begin{array}{l}\text { A utilização de agregados graúdos reciclados } \\
\text { provenientes de resíduos de alvenaria cerâmica } \\
\text { e de blocos de concreto com EPS em sua } \\
\text { composição permitiu a produção de concretos } \\
\text { com massa específica abaixo de } 2,0 \mathrm{~g} / \mathrm{cm}^{3} \text {, } \\
\text { caracterizando-os como concretos leves. } \\
\text { Os resultados de resistência à compressão } \\
\text { mostraram que os concretos leves produzidos } \\
\text { com os agregados reciclados porosos } \\
\text { apresentaram resistências relativamente baixas, } \\
\text { inferiores às dos concretos produzidos com } \\
\text { agregados de argila expandida (artificiais). }\end{array}$ \\
\hline
\end{tabular}

No trabalho de Rocha et al. (2016), concluiu-se que a resistência à compressão, a trabalhabilidade e a densidade são as propriedades do concreto que mais sofrem influência da adição de EPS. A variação no valor do abatimento ocorreu devido a influência do aumento das proporções de EPS indicando maior fluidez, mesmo assim, apresentou boas condições de trabalhabilidade.

De acordo com Silva et al. (2017), o EPS não possui boa absorção de água, assim, houve alteração no slump test em comparação com o concreto convencional, corroborando com o aumento da fluidez, o que deixa o concreto com maior trabalhabilidade.

Entretanto, no trabalho de Xavier et al. (2016) os resultados foram diferentes em relação ao abatimento de tronco, nesse estudo foi observado que quando se aumenta o teor de EPS no concreto, o 
resultado será um concreto menos trabalhável.

Avaliando os três artigos, pode-se concluir que os trabalhos em que houve aumento da trabalhabilidade em função do aumento do EPS, foi realizado a substituição de uma porcentagem de agregado por EPS e realizado a dosagem normalmente. Já no trabalho de Xavier et al. (2016), foi realizado o acréscimo de EPS mantendo o fator de água/cimento fixo, assim ao se adicionar este agregado leve, foi verificado menor trabalhabilidade.

Quanto a resistência, Carvalho et al. (2019) afirmam que a adição de EPS no concreto resultou em uma perda de desempenho de cerca de $40 \%$, chegando a $50 \%$ de redução quando se substituiu todo agregado graúdo e $17,7 \%$ do agregado miúdo por EPS.

Segundo Silva et al. (2017), para ser considerado um concreto leve, o mesmo deve apresentar uma resistência mínima de $17 \mathrm{Mpa}$. Nesse contexto apenas as amostras com substituição parcial de 10\% e 15\% do agregado graúdo por pérolas de EPS foram aprovados, a amostra com 20\% de EPS para o agregado graúdo foi reprovado por não apresentar a resistência à compressão axial mínima exigida.

No trabalho utilizando metodologia experimental realizado por Rocha et al. (2016), onde o traço de referência apresentou resultado de 21,13 Mpa aos 28 dias, a substituição do agregado graúdo por EPS se mostrou eficiente nas proporções de 5\% que apresentou resistência de 20,53 Mpa e a de 10\% com resistência de 20,21 Mpa. Já o traço com adição de 15\%, apresentou uma resistência média de 18,45 Mpa, resistência essa, considerada abaixo do mínimo de norma para concreto estrutural.

No trabalho de Gomes et al. (2015), onde foram utilizados agregados reciclados tanto no agregado graúdo como no agregado miúdo, foi verificado uma baixa resistência para os concretos produzidos com adição de EPS reciclado, os autores recomendaram a utilização do concreto para funções não estruturais.

Kumayama et al. (2015), afirma que a variação da resistência em função da substituição do agregado graúdo e miúdo por EPS, oferece um bom indicativo para formulação de um modelo de dosagem para o comportamento mecânico, que permita adotar um teor de EPS ideal para a finalidade em que se pretende utilizar o concreto leve.

De acordo com Moncada et al. (2019), o uso do EPS reduz a resistência dos componentes estruturais, entretanto não significa que o mesmo não possa ser utilizado como elementos estruturais, pois, sua resistência foi superior ao valor mínimo de 20 Mpa de acordo com a norma NBR 6118:2014. Assim, esse concreto leve, quando utilizado, apresenta melhor desempenho que o concreto convencional, visto que o peso próprio da estrutura é reduzido significativamente.

Na revisão de Dantas et al. (2019), mostra que os resultados obtidos em ensaios com diversos percentuais de pérolas de Poliestireno Expandido indicam que o material é promissor na confeç̧ão de concreto leve para diversas aplicações, com ressalva na sua limitação devido à resistência variável. Assim, o autor recomenda um estudo acerca das propriedades mínimas admissíveis para a melhor utilização desse tipo de concreto.

Quanto ao desempenho térmico, Bezerra (2003) afirma que o desempenho térmico de blocos com EPS como agregado, apresenta grandes vantagens em relação ao bloco de 8 furos e ao bloco de cimento 
vazado. Podendo corresponder a uma diferença de $181,1 \%$ de eficiência térmica do bloco de concreto leve com EPS para o bloco convencional.

Corroborando com essa afirmação Carvalho et al. (2019), demostraram que as propriedades térmicas de concretos produzidos com adição de EPS apresentam melhor desempenho em comparação com o concreto convencional. Os resultados mostraram no modelo experimental uma diminuição da temperatura nas faces das placas e no interior do compartimento e ainda verificou atraso na ascensão da temperatura. No concreto produzido com maior teor de EPS, foi registrado o melhor desempenho térmico com de $6^{\circ} \mathrm{C}$ em comparação com o traço de referência.

\section{CONCLUSÕES}

Com base nessa revisão de literatura, foi possível levantar algumas conclusões a respeito da adição de EPS como agregado na confecção de concreto leve. O primeiro ponto a ser analisado, é a existência de diferentes metodologias de produção de concreto com adição de EPS, o que provoca grandes variações das propriedades dos produtos finais, como verificados em alguns trabalhos o aumento da trabalhabilidade com o acréscimo de EPS, já em outros casos, ocorreu a diminuição da mesma com o aumento da proporção do EPS. Essa constatação demonstra a necessidade de uma padronização da adoção de Poliestireno Expandido como agregado, podendo ser feito através de uma proposta de um método de dosagem e futuramente uma norma com os padrões de desempenho mínimo para esse tipo de concreto.

Quanto à resistência, é unânime e lógico que a adição de EPS no concreto reduz a capacidade de resistência do elemento, entretanto nos trabalhos é possível perceber que existe uma taxa de acréscimo que gira em torno de $15 \%$ a $20 \%$ que o concreto fica dentro dos limites estabelecidos de norma, nesses casos, a adição de EPS torna-se vantajosa por diminuir o peso próprio da estrutura, reduzindo a quantidade de material necessário para resistir aos esforços, além de toda a contribuição ao meio ambiente, por poupar recursos naturais e ainda a possibilidade de se utilizar resíduos recicláveis de EPS na sua produção.

Além dessas vantagens citadas, foi verificado grande potencialidade no desempenho térmico do concreto leve com adição de EPS, no viés sustentável, um melhor desempenho térmico resulta na economia de energia de uma residência. Quanto a grande desvantagem da utilização do EPS no concreto, foi verificado basicamente a inexistência de um método de dosagem que padronize as propriedades do concreto produzido, pois essa carência gera grande variações dos resultados, onde para o setor da construção, é exigido uma padronização e estabelecimento de padrões mínimos esperado de comportamento do concreto.

\section{REFERÊNCIAS}

BEZERRA, L. A. C.. Análise do desempenho térmico de sistema construtivo de concreto com EPS como agregado graúdo. Dissertação (Mestrado) - Universidade Federal do Rio Grande do Norte, Natal, 2003

CARVALHO, C. H. R.; MOTTA, L. A. C.. Estudo de concreto com poliestireno expandido reciclado. Revista IBRACON de Estruturas e Materiais, v.12, n.6, p.1390-1407, 2019.
CORDEIRO, A. M.; OLIVEIRA, G. M.; RENTERÍA, J. M.; GUIMARÃES, C. A.. Revisão sistemática: uma revisão narrativa. Rev. Col. Bras. Cir., v.34, n.6, p.428-431, 2007.

DANTAS, J. G. O.; COELHO, D. C. L.. Análise comparativa do desempenho do concreto leve com adição de poliestireno expandido (EPS). Monografia (Graduação) - Universidade Federal Rural do Semiárido, Mossoró, 2019. 
GOMES, P. C. C.; VIEIRA, N.; ALENCAR, T. F.. Obtenção de concreto leve utilizando agregados reciclados. Ambiente Construído, v.15, n.3, p.31-46, 2015.

KUMAYAMA, R.; ALCÂNTARA, M. A. M.; CRUZ, W. S.; SEGANTINI, A. A. S.. Estudo da viabibilidade do emprego de pó de mármore para produção de concreto auto-adensável e substituição parcial dos agregados por pérolas de Poliestireno Expandido EPS. Revista Eletrônica de Engenharia Civil, v.10, n.2, 2015. DOI: https://doi.org/10.5216/reec.v10i2.33117

NEVES, J. L.; SCHWARTZ, E.; GUANILO, M. E. E.; AMESTOY, S. C.; MENDIETA, M. C.; LISE, F.. Avaliação da satisfação de familiares de pacientes atendidos em unidades de terapia intensiva: revisão integrativa. Texto \& Contexto, 2018.

MONCADA, J. E. C. M.; FLOR, L.; SILVA, V.; PACHECO, J.. Estudo da adição de argila expandida e EPS como agregados na elaboração de concreto leve. Revista Eletrônica TECCEN, v.12, n.1, p.02-07, 2019.

MORAES, C.; BRASIL, P.. Estudo da Viabilidade do Poliestireno Expandido (EPS) na produção de edificações com baixo impacto ambiental. In: SEMINÁRIO NACIONAL DE CONSTRUÇÕES SUSTENTÁVEIS, 4; FÓRUM DESEMPENHO
DAS EDIFICAÇÕES, 1. Anais. Eficiência Energética do Ambiente Construído, 2015.

ROCHA, B. F. M.; FIGUEIREDO, F. B.; ALTRAN, D. A.. Estudo das propriedades físicas e mecânicas do concreto leve com agregados de Poliestireno Expandido (EPS). In: CONGRESSO TÉCNICO CIENTÍFICO DA ENGENHARIA E DA AGRONOMIA. Anais. 2016. p.1-5.

ROHAN, U.; SOARES, C. A. P.; FRANÇA, S. L. B.; MEIRIÑO, M. J.. A formação do engenheiro civil inovador brasileiro frente aos desafios da tecnologia, do mercado, da inovação e da sustentabilidade. In: CONGRESSO NACIONAL DE EXCELÊNCIA EM GESTÃO, 12. Anais. 2016

SILVA, D. A.; SILVESTRE, G. S.; CARNEIRO NETO, M. M.. Substituição de agregados por Poliestireno Expandido (EPS) no concreto leve. In: CONGRESSO NACIONAL DE EXCELÊNCIA EM GESTÃO, 12; INOVARSE: RESPONSABILIDADE SOCIAL APLICADA, 3. Anais. 2017.

XAVIER, B. C.; BASSANI, F.; MENDES, A. S.. Avaliação do Concreto Leve Estrutural com EPS Reciclado. Periódico Eletrônico Fórum Ambiental da Alta Paulista, v.12, n.3, 2016.

A CBPC - Companhia Brasileira de Produção Científica (CNPJ: 11.221.422/0001-03) detém os direitos materiais desta publicação. Os direitos referem-se à publicação do trabalho em qualquer parte do mundo, incluindo os direitos às renovações, expansões e disseminações da contribuição, bem como outros direitos subsidiários. Todos os trabalhos publicados eletronicamente poderão posteriormente ser publicados em coletâneas impressas sob coordenação da Sustenere Publishing, da Companhia Brasileira de Produção Científica e seus parceiros autorizados. Os (as) autores (as) preservam os direitos autorais, mas não tem permissão para a publicação da contribuição em outro meio, impresso ou digital, em português ou em tradução. 